\title{
Laparoscopic ventral rectopexy is the gold standard treatment for rectal prolapse
}

\author{
F. Reche $^{1,2} \cdot$ J.-L. Faucheron ${ }^{1,2}$
}

Received: 17 May 2015/Accepted: 25 May 2015/Published online: 8 September 2015

(C) Springer-Verlag Italia Srl 2015

Several procedures have been described to treat rectal prolapse [1]. The aims of the surgical treatment are to correct the anatomical abnormality and to cure the accompanying symptoms of incontinence, constipation and pain, with the lowest rate of complications as possible and an acceptable rate of recurrence.

Two approaches are possible. The perineal approach is associated with a high recurrence rate and, as a result, is only advocated for patients who are not candidates for an abdominal operation [1]. It is nowadays generally accepted that the abdominal procedures carry a lower recurrence rate and improved functional outcome and they are therefore preferred to the perineal procedures [2]. Since its first description by Orr in 1953, rectopexy has evolved through years and has become the procedure of choice in cases of total rectal prolapse and also in cases of other kinds of posterior pelvic floor dysfunction such as internal rectal prolapse and enterocele [3]. The procedure became so popular that 14 articles about it were published in this journal in a period of less than 3 years.

The abdominal techniques described up to now differ as regards approach (open vs. laparoscopic vs. robotic), extent of rectal mobilization (anterior vs. anterior and posterior vs. complete mobilization), addition or omission of a sigmoid resection, excision or not of the pouch of Douglas, methods used for mesh fixation, and type, size, nature and number of meshes used for the pexy.

\section{J.-L. Faucheron}

JLFaucheron@chu-grenoble.fr

1 Colorectal Unit, Department of Surgery, Michallon University Hospital, CS 10217, 38043 Grenoble Cedex, France

2 Grenoble Alpes University, Grenoble, France
However, several changes were made in the traditional rectopexy procedure some of which became the gold standard.

First, Cadeddu et al. [4] recently reported in a review that laparoscopic rectopexy is safe and equivalent to the open procedure in terms of technical results, recurrence, incontinence and constipation. Robotic-assisted laparoscopic rectopexy is also safe and feasible, and short-term results are comparable with those of conventional laparoscopic rectopexy. However, Mäkelä-Kaikkonen et al. [5] found no arguments to support the routine use of robotic assistance in rectopexy operations. The laparoscopic approach is currently the gold standard.

Second, rectal mobilization should be limited strictly to the anterior wall of the low rectum, in order not to damage autonomic nerves [3]. Most surgeons now perform the socalled D'Hoore operation, which is a ventral rectopexy and recognized as the gold standard [1].

Third, comparison between laparoscopic resection rectopexy (removing the sigmoid colon) and laparoscopic rectopexy seems to favor the second procedure: It was demonstrated by Formijne Jonkers et al. [6] last year that both operations were effective and offered significant improvements in functional symptoms, but laparoscopic resection rectopexy had a higher complication rate than laparoscopic rectopexy. Thus, the gold standard seems to be rectopexy without sigmoidectomy.

Fourth, Douglas pouch removal was part of the original procedure and is probably one of the reasons why the recurrence rate is so low (around 3\% in the long term) [1]. The rationale for that is based on the fact that in patients suffering from rectal prolapse, one of the anatomical abnormalities is the deep Douglas pouch. Subsequently, excision of the redundant peritoneal cul-de-sac might well decrease the risk of prolapse recurrence. Plication of the 
incised peritoneum is similar to this gold standard approach.

Fifth and lastly, the literature fails to provide any data that indicate what the gold standard is for mesh prostheses in rectopexy resorbable or not, shape, number and fixation method. There will probably be a passionate debate about this in the coming years.

\section{Compliance with ethical standards}

Conflict of interest The authors declare that they have no conflict of interest.

Ethical approval For this type of study ethical approval is not necessary.

Informed consent For this type of study informed consent is not required.

\section{References}

1. Faucheron J-L, Trilling B, Girard E, Sage PY, Barbois S, Reche F (2015) Anterior rectopexy for full-thickness rectal prolapse: technical and functional results. World $\mathrm{J}$ Gastroenterol 21:5049-5055

2. Maggiori L, Bretagnol F, Ferron M, Panis Y (2013) Laparoscopic ventral rectopexy: a prospective long-term evaluation of functional results and quality of life. Tech Coloproctol 17:431-436

3. Lauretta A, Bellomo RE, Galanti F, Tonizzo CA, Infantino A (2012) Laparoscopic low ventral rectocolpopexy (LLVR) for rectal and rectogenital prolapse: surgical technique and functional results. Tech Coloproctol 16:477-483

4. Cadeddu F, Sileri P, Grande M, De Luca E, Franceschilli L, Milito G (2012) Focus on abdominal rectopexy for full-thickness rectal prolapse: meta-analysis of literature. Tech Coloproctol 16:37-53

5. Mäkelä-Kaikkonen J, Rautio T, Klintrup K et al (2014) Roboticassisted and laparoscopic ventral rectopexy in the treatment of rectal prolapse: a matched-pairs study of operative details and complications. Tech Coloproctol 18:151-155

6. Formijne Jonkers HA, Maya A, Draaisma WA et al (2014) Laparoscopic resection rectopexy versus laparoscopic ventral rectopexy for complete rectal prolapse. Tech Coloproctol 18:641-646 